\title{
Human tonsil-derived mesenchymal stromal cells enhanced myelopoiesis in a mouse model of allogeneic bone marrow transplantation
}

\author{
JUNG-HWA RYU ${ }^{1 *}$, MINHWA PARK ${ }^{1 *}$, BO-KYUNG KIM ${ }^{1}$, YU-HEE KIM ${ }^{1}$, \\ SO-YOUN WOO ${ }^{1}$ and KYUNG-HA RYU ${ }^{2}$
}

Departments of ${ }^{1}$ Microbiology and ${ }^{2}$ Pediatrics, School of Medicine, Global Top 5 Research Program, Ewha Womans University, Seoul 158-710, Republic of Korea

Received April 1, 2015; Accepted December 2, 2015

DOI: $10.3892 / \mathrm{mmr} .2016 .5604$

\begin{abstract}
Mesenchymal stromal cells (MSCs) have therapeutic potential for repairing tissue damage and are involved in immune regulation. MSCs are predominantly isolated from bone marrow (BM), adipose tissue or placental tissue. Further to these well-known sources, the isolation of MSCs from human tonsils was previously reported. The aim of the present study was to investigate a potential role for tonsil-derived MSCs (T-MSCs) in BM reconstitution and application towards supplementing hematopoiesis in a mouse model of BM transplantation (BMT). Eight-week-old BALB/c female mice received $80 \mathrm{mg} / \mathrm{kg}$ busulfan $(\mathrm{Bu}) / 200 \mathrm{mg} / \mathrm{kg}$ cyclophosphamide (Cy) conditioning chemotherapy for BM ablation. Subsequently, human T-MSCs were injected into the $\mathrm{Bu} / \mathrm{Cy}$-treated mice with or without BM cells (BMCs) obtained from allogeneic C57BL/6 male mice. After 3 weeks, peripheral blood and BM was collected for analysis. The red blood cell count in the group that received BMCs had almost returned to normal, whereas mononuclear cell counts and BM cellularity were most improved in the T-MSCs + BMCs group. These results indicate that the T-MSCs enhanced myelopoiesis in the allogeneic BMT mouse model, as evidenced by the restoration of BM with hematopoietic cells, as well as increased myeloid colony formation in vitro. Therefore, T-MSCs may provide a source of MSCs to facilitate myelopoiesis and megakaryocytosis following BMT.
\end{abstract}

Correspondence to: Dr Kyung-Ha Ryu, Department of Pediatrics, School of Medicine, Global Top 5 Research Program, Ewha Womans University, 1071 Anyangcheon-ro, Yangcheon-gu, Seoul 158-710, Republic of Korea

E-mail: ykh@ewha.ac.kr

${ }^{*}$ Contributed equally

Key words: tonsil-derived mesenchymal stromal cells, myelopoiesis, methylcellulose colony-forming assay, bone marrow transplantation

\section{Introduction}

Mesenchymal stromal cells (MSCs) are defined as self-renewing progenitor cells with multi-lineage potential that differentiate into cells of mesodermal origin, including adipocytes, osteocytes, and chondrocytes, as well as non-mesodermal cells (1-4). MSCs are easily isolated from bone marrow (BM), adipose and other tissues, and have immune modulatory properties, including low antigenicity. Furthermore, MSCs secrete various chemicals to promote tissue preservation and regeneration, and to inhibit inflammation and fibrosis $(5,6)$. Clinical investigations into the therapeutic potential of MSCs in various diseases are rapidly evolving. Previous studies have demonstrated that co-administration of MSCs with hematopoietic stem cells (HSCs) in allogeneic HSC transplantation (HSCT) accelerated hematopoietic recovery $(7,8)$, ameliorated graft-versus-host disease (GVHD) (9-11) and promoted tissue regeneration $(12,13)$.

Allogeneic HSCT is a routine treatment for intractable hematologic malignancies (14). Previous studies have indicated that co-transplantation of BM-derived MSCs with donor HSCs promoted hematopoietic cell engraftment, prevented or treated GVHD, and accelerated marrow stromal regeneration (11). The use of MSCs in HSCT with HSCs enhanced long-term engraftment of human cells in animal models $(15,16)$ and promising results regarding the enhancement of myelocytic or megakaryocytic engraftment in the co-transplantation of MSCs with HSCs have also been reported (17).

MSCs have been previously isolated from human tonsils and termed tonsil-derived MSCs (T-MSCs) (18). T-MSCs were demonstrated to exhibit the stem cell characteristics of self-renewal and proliferation, with the ability to differentiate into adipocytes, osteocytes and chondrocytes. Furthermore, the cells expressed endodermal markers and parathyroid cell markers (18), and were differentiated into hepatocyte-like cells (19). The authors hypothesized that T-MSCs may be equivalent to BM-derived MSCs with respect to induction or supplemental effects on BM reconstitution. T-MSCs were also hypothesized to be beneficial in hematopoiesis following BM transplantation (BMT). In the present study, a possible role 
and beneficial effect for T-MSCs in BM reconstitution was investigated using an allogeneic BMT mouse model.

\section{Materials and methods}

Animals. Eight-week-old female BALB/c (H-2d) mice and male C57BL/6 (H-2b) mice were purchased from Orient Bio, Inc. (Seongnam, South Korea). Mice were housed separately at $21-23^{\circ} \mathrm{C}, 51-54 \%$ humidity with a 12 -h light/dark cycle, and had access to food and water ad libitum. All animal studies were approved by the Animal Care and Use Committee at Ewha Medical School (Seoul, South Korea) and conformed to international standards.

Culture of T-MSCs. T-MSC separation was performed as described previously (18). Surgically removed palatine tonsils were collected from patients (age, $<10$ years) undergoing tonsillectomy due to benign hypertrophic tonsils between September 2011 and December 2012. Informed written consent was obtained from all patients who participated in the study, and the study protocol was approved by the Institutional Review Board of Ewha Womans University Medical Center (Mok-Dong Hospital, Seoul, South Korea). The tonsil tissues were minced with scissors and digested in RPMI-1640 medium (Invitrogen; Thermo Fisher Scientific, Inc., Waltham, MA, USA) containing $210 \mathrm{U} / \mathrm{ml}$ collagenase type I (Invitrogen; Thermo Fisher Scientific, Inc.) and $10 \mu \mathrm{g} / \mathrm{ml}$ DNase (Sigma-Aldrich, St. Louis, MO, USA) for $30 \mathrm{~min}$ at $37^{\circ} \mathrm{C}$. Mononuclear cells were obtained from the digested tonsil tissue by Ficoll ${ }^{\circledast}$ Paque density gradient centrifugation (300 x g for $30 \mathrm{~min}$ at room temperature with brake-off; GE Healthcare, Chalfont, UK). The cells were plated at a density of $1 \times 10^{7}$ cells/100-mm diameter culture dish in Dulbecco's modified Eagle's medium containing 10\% fetal bovine serum, $100 \mu \mathrm{g} / \mathrm{ml}$ streptomycin and $100 \mathrm{U} / \mathrm{ml}$ penicillin all from Welgene, Inc. (Gyeongsan-si, Korea). After 48 h, non-adherent cells were removed from the medium and adherent mononuclear cells (the T-MSCs) were placed in fresh culture medium. T-MSCs were labeled using the PKH26 MINI kit (Sigma-Aldrich) according to the manufacturer's protocol. Cells were re-suspended in phosphate-buffered saline (PBS; Sigma-Aldrich) $\left(5 \times 10^{6}\right.$ cells $\left./ \mathrm{ml}\right)$ for injection into mice.

Isolation and preparation of murine BMCs. Eight-week-old C57BL/6 male mice were sacrificed by cervical dislocation and the lower limbs (femurs and tibias) were collected. BMCs were harvested, following dissection and cleaning of the bones, by removing the ends of each bone and flushing the medullary cavities with serum-free RPMI-1640 medium (Welgene, Inc.) using a 25-gauge needle (Korea Vaccine, Ansan-si, Korea). A single cell suspension was produced by passing the BM suspension through a sterile $70-\mu \mathrm{m}$ cell strainer (SPL Life Sciences, Pocheon, South Korea) and the filtrate was centrifuged at $300 \mathrm{x} \mathrm{g}$ for $5 \mathrm{~min}$. Isolated BMCs were incubated in red blood cell (RBC) lysis solution (Sigma-Aldrich; $0.15 \mathrm{M} \mathrm{NH}_{4} \mathrm{Cl}, 10 \mathrm{mM} \mathrm{NaHCO}_{3}$ and $10 \mathrm{mM}$ disodium EDTA, all from Sigma-Aldrich) for 2 min followed by two washes with PBS. Following resuspension with PBS, $2 \times 10^{6}$ cells $/ 200 \mu \mathrm{l}$ were intravenously injected into recipient mice using 1-ml syringes (Sungshim, Bucheon-si, Korea).
Experimental design for recipient conditioning and BMT. Eight-week-old female BALB/c recipient mice received busulfan (Bu; Sigma-Aldrich) and cyclophosphamide (Cy; Baxter, Los Angeles, CA, USA) combination conditioning therapy. Bu $(20 \mathrm{mg} / \mathrm{kg}$ ) was injected on days 12,3 and 4 , followed by administration of Cy $(100 \mathrm{mg} / \mathrm{kg})$ on days 5 and 6 via intraperitoneal injection. Following one day of recovery, infusion of T-MSCs or T-MSCs + BMCs was performed on day 8 according to the following procedure. BMCs from donor mice were injected via the tail vein into each recipient mouse. The mice were divided into five groups, as follows: i) The control, no treatment group; ii) the $\mathrm{Bu} / \mathrm{Cy}$ chemotherapy group, iii) the T-MSCs (following $\mathrm{Bu} / \mathrm{Cy}$ ) group; iv) the T-MSCs + BMCs (following $\mathrm{Bu} / \mathrm{Cy}$ ) group; and the BMCs (following $\mathrm{Bu} / \mathrm{Cy}$ ) group. All mice were administered with water containing antibiotics for 3 weeks to prevent bacterial infection.

Hematological and histological analysis. Three weeks after cell transplantation (day 28), the mice were anesthetized with Zoletil (0.012 ml/20 g body weight; Virbac, St. Louis, USA) and Rompun $(0.008 \mathrm{ml} / 20 \mathrm{~g}$ body weight; Bayer Korea, Seoul, Korea) and blood ( $1 \mathrm{ml}$ ) was collected by cardiac puncture into heparin-coated 1-ml syringes (JWphama, Seoul, Korea). Blood cells were counted using a Neubauer chamber and blood smear slides were prepared for staining. Peripheral blood smears were air-dried and dipped in methanol (Duksan, Ansan-si, Korea) three times for fixation, followed by Diff-Quik staining (Sysmex Corporation, Kobe, Japan). The femurs of each mouse were isolated following cervical dislocation, and immediately fixed with 4\% paraformaldehyde (Sigma-Aldrich) and decalcified for embedding in paraffin (Korea Animal Medical Science Institute, Guri-si, Korea). BM sections $(4 \mu \mathrm{m})$ were stained with hematoxylin and eosin (H\&E; Sigma-Aldrich) and images of the tissue sections were captured using a BX-50 microscope and a DP-71 digital camera and imaging system (DPController 3.2.276.2) (all from Olympus Corp., Tokyo, Japan). Histological analysis was conducted using Image J software version 1.49 (National Institutes of Health, Bethesda, MD, USA) by selecting adipocytes in the BM using a color threshold. Other cells (erythroid and myeloid cells) were selected for BM area measurement.

Methylcellulose colony-forming assay. To analyze the colony-forming unit derived from hematopoietic stem cells, $5 \times 10^{5}$ cells were mixed with $4 \mathrm{ml}$ MethoCult ${ }^{\circledR}$ media (Stemcell Technologies, Inc., Vancouver, BC, Canada). The mixture was allowed to stand for $3 \mathrm{~min}$ to remove bubbles and a 1-ml mixture was dispensed by pipette for each $30-\mathrm{mm}$ cell culture dish (triplicate assay). Cells were incubated for 3 weeks in a $5 \% \mathrm{CO}_{2}$ incubator at $37^{\circ} \mathrm{C}$ with humidifying water-containing dishes. After 3 weeks of culture, the total colony was counted under an optical microscope (Olympus CKX41; Olympus Corp.) over a grid plate according to the shape and the size of the colonies.

Statistical analysis. The values are expressed as the mean \pm standard error of the mean. The differences between groups were analyzed via two-way analysis of variance and Student's t-test using GraphPad Prism 6.04 software (GraphPad Software Inc., La Jolla, CA, USA). P $<0.05$ was considered to indicate a statistically significant difference. 
$\mathbf{A}$

Sacrificing and

obtaining blood,

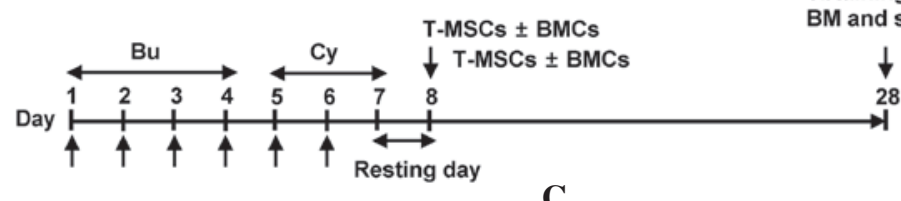

C
B

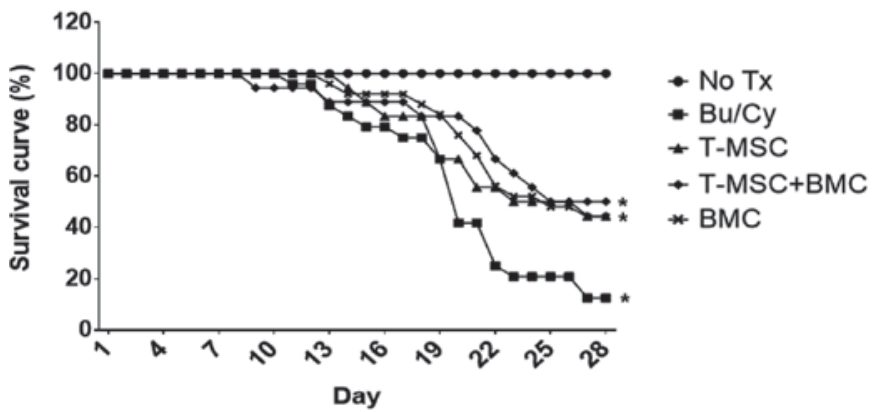

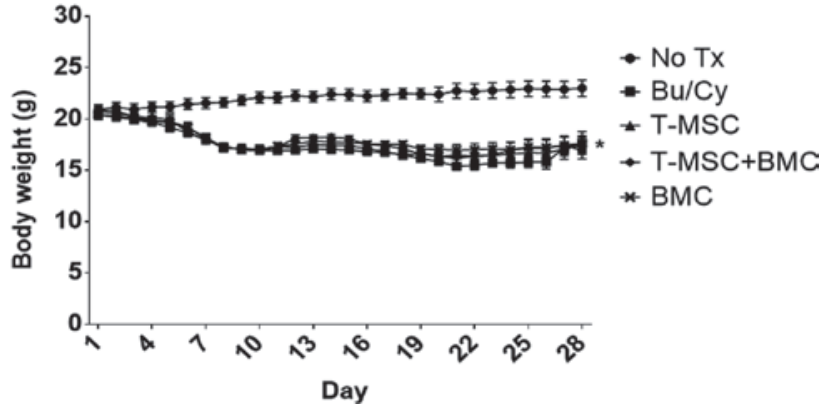

Figure 1. BMT model design and follow-up observation. (A) Schematic demonstrating the time course of the conditioning regimen and mouse BMT experiment. Following one day of recovery (day 7), human T-MSCs $\left(2 \times 10^{6}\right.$ cells) \pm mouse BMCs $\left(2 \times 10^{6}\right.$ cells) were injected intravenously via the tail vein (day 8). The mice were divided into 5 groups as follows: The control group (no Tx; n=9); the Bu/Cy chemotherapy group (Bu/Cy; n=16); the T-MSCs following Bu/Cy group (T-MSC; $\mathrm{n}=16$ ); the T-MSCs + BMCs following Bu/Cy treatment group (T-MSC + BMC; $\mathrm{n}=10$ ); and the BMCs following Bu/Cy treatment group ( $\mathrm{n}=15$ ). (B) Kaplan-Meier survival curve. The cumulative survival rate in the T-MSCs + BMCs group was higher than any other treatment group ("P $<0.05$ vs. control). (C) Body weight changes were monitored immediately following $\mathrm{Bu} / \mathrm{Cy}$ treatment until 3 weeks after cell injection (" $\mathrm{P}<0.05 \mathrm{vs}$. control). Values are expressed as the mean. BMT, bone marrow transplantation; $\mathrm{BMC}$, bone marrow cell; $\mathrm{Bu}$, busulfan; $\mathrm{Cy}$, cyclophosphamide; T-MSC, tonsil-derived mesenchymal stromal cells; Tx, treatment.

A

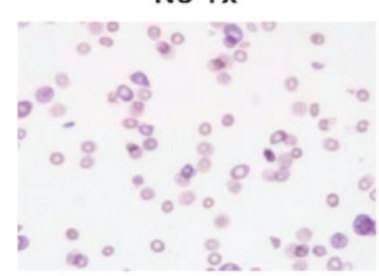

T-MSCs+BMCs

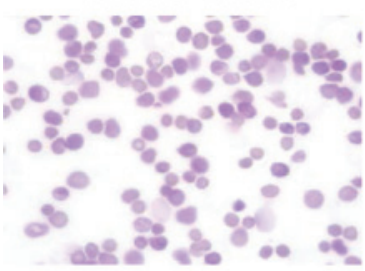

B

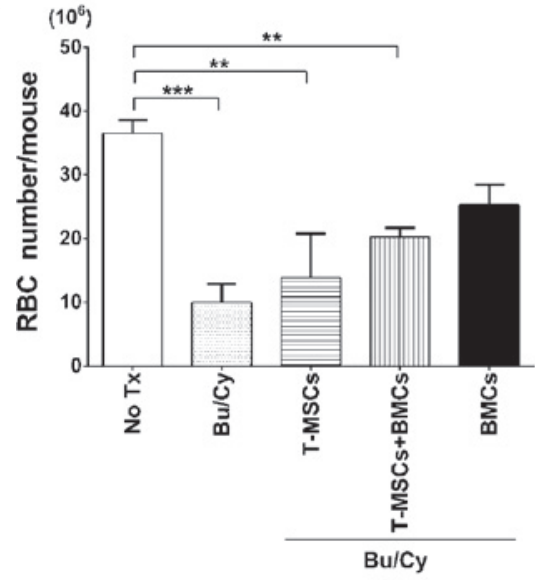

$\mathrm{Bu} / \mathrm{Cy}$

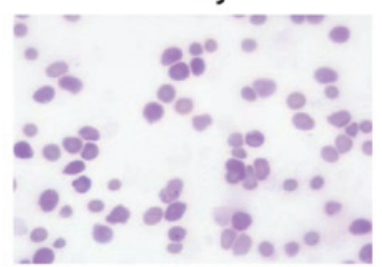

BMCs

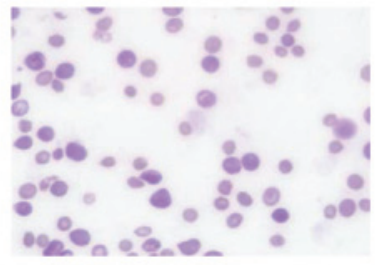

C $\left(10^{5}\right)$

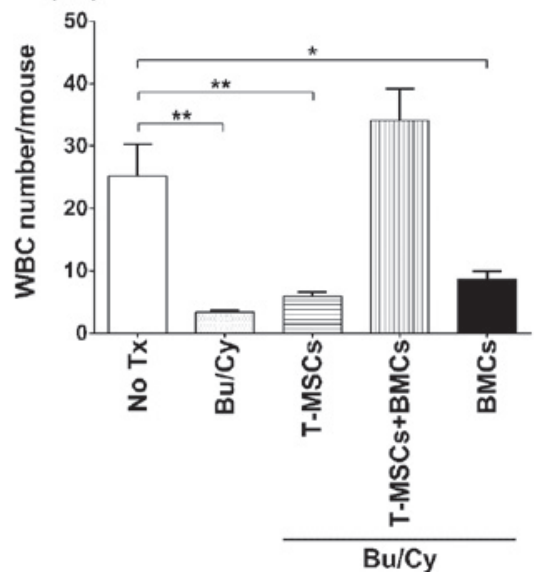

Figure 2. Peripheral blood morphology and complete blood counts. (A) Peripheral blood smear of control mice demonstrated normal erythrocytes, WBCs, including polymorphonuclear leucocytes and mononuclear cells, and platelets. Peripheral blood smears were stained with Diff-Quik; magnification, x1,000. (B) RBC and (C) WBC counts were performed and a t-test was used to compare each value with the control ( $\mathrm{P}<0.05,{ }^{* * *} \mathrm{P}<0.01$ and $\left.{ }^{* * *} \mathrm{P}<0.0001\right)$. Values are expressed as the mean \pm standard error of the mean. BMT, bone marrow transplantation; BMC, bone marrow cell; Bu, busulfan; Cy, cyclophosphamide; T-MSC, tonsil-derived mesenchymal stromal cells; Tx, treatment; RBC, red blood cell; WBC, white blood cell. 

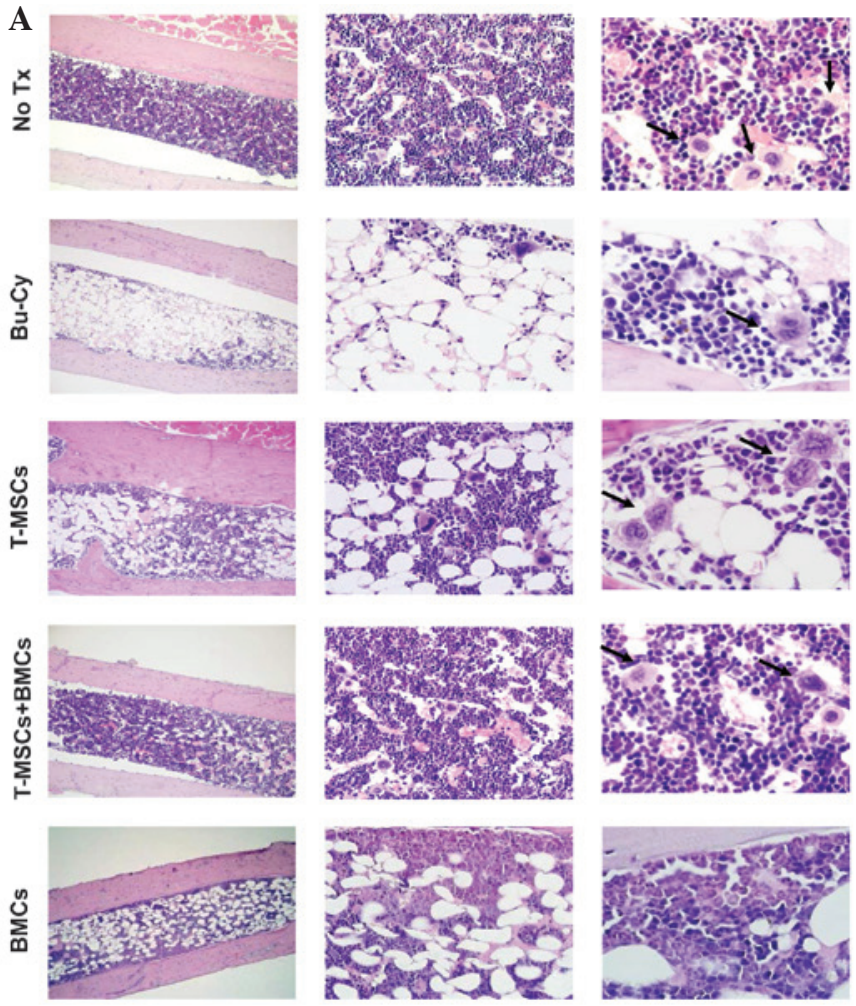

C

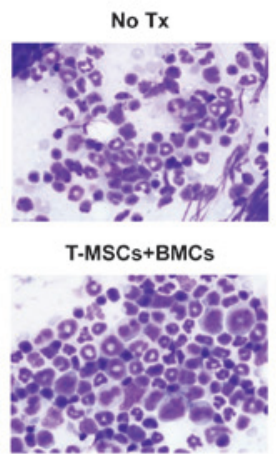

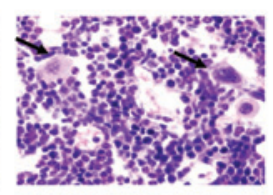
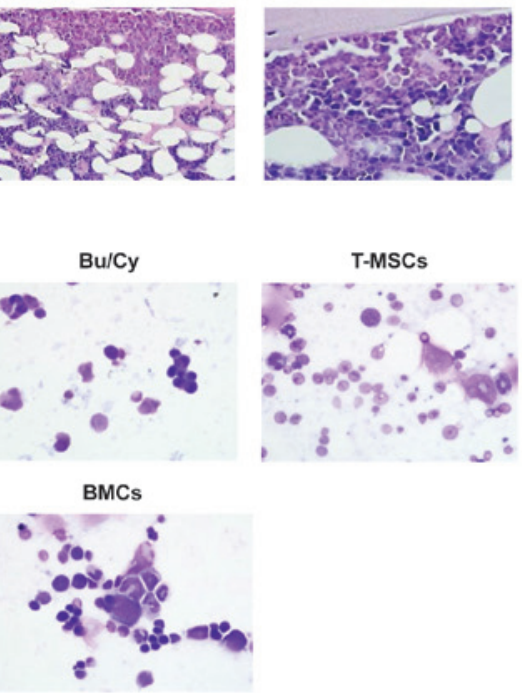

B
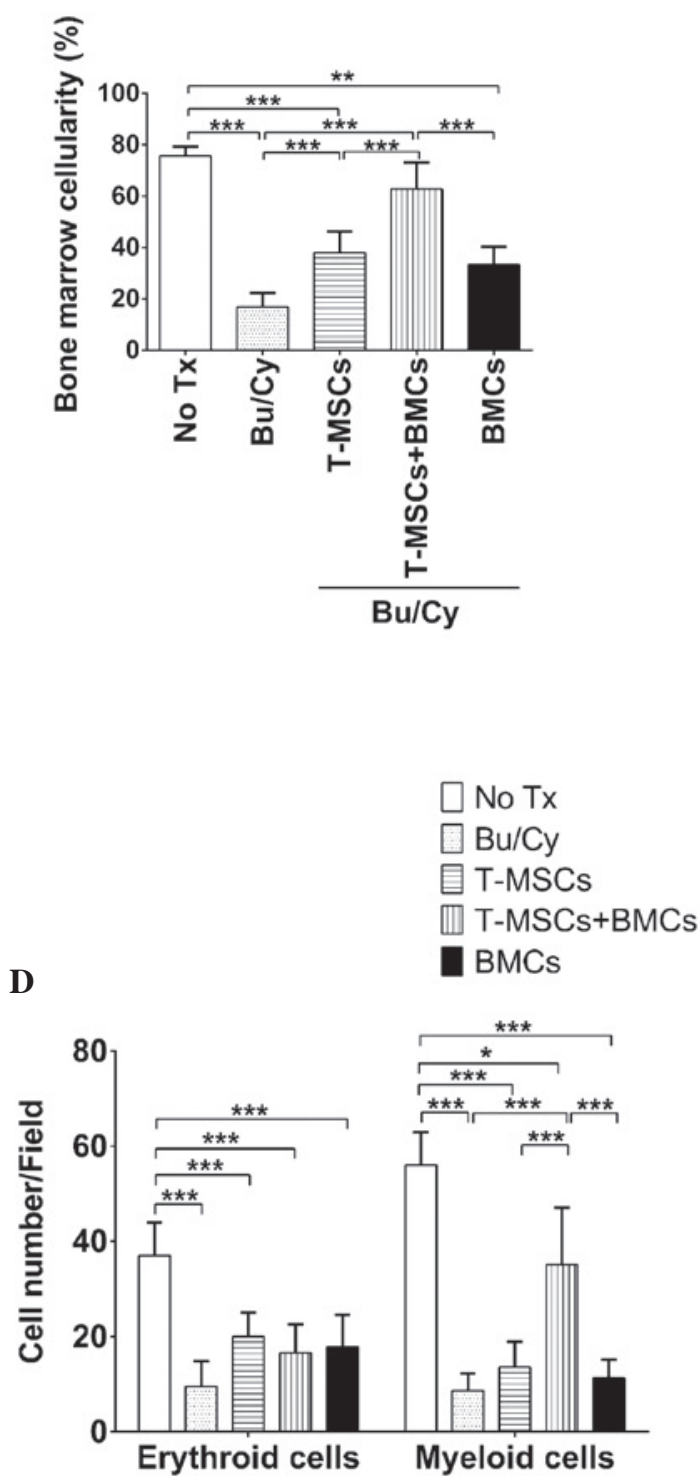

Figure 3. Hematopoiesis in BM. (A) Representative BM histology and cellularity in the tibias of experimental mice. Magnification: Left column, x100; middle column, $x 400$; right column, x1,000. Arrows indicate megakaryocytes. (B) BM cellularity was obtained by calculating the ratio of marrow cells to adipocytes in 10 different fields from each slide ( $\mathrm{n}=5$ /group). BM cellularity was analyzed by Image $\mathrm{J}$ software using the ratio of the area occupied by marrow cells to adipocytes in $>10$ different fields on each slide ( ${ }^{*} \mathrm{P}<0.05,{ }^{* *} \mathrm{P}<0.01$ and $\left.{ }^{* * *} \mathrm{P}<0.001\right)$. (C) Peripheral blood smears were stained with Diff-Quik (magnification, x1,000). (D) BM smear demonstrated the hematopoietic lineage cells in BM. The data indicates the cell number for each group obtained from $>10$ different fields in the samples ( ${ }^{*} \mathrm{P}<0.05$ and $\left.{ }^{* * *} \mathrm{P}<0.0001\right)$. Values are expressed as the mean \pm standard error of the mean. BM, bone marrow; BMT, bone marrow transplantation; BMC, bone marrow cell; Bu, busulfan; Cy, cyclophosphamide; T-MSC, tonsil-derived mesenchymal stromal cells; Tx, treatment.

\section{Results}

Co-transplantation of T-MSCs with BMCs improved survival in the allogeneic mouse of BMT. The degree of BM restoration in the mice was compared between the groups that received BMCs with or without T-MSCs following allogeneic BMT. Recipient female BALB/c mice were injected with $\mathrm{Bu} / \mathrm{Cy}$ for 6 days (resulting in $\mathrm{BM}$ ablation), allowed to rest for one day, then injected with T-MSCs, with or without BMCs from C57BL/6 male mice (Fig. 1A). During the 3 weeks following cell transfer, the mice were followed up and survival was compared between the groups. The mean survival was $100 \%$ in the control group $(17 / 17), 12.5 \%$ in the $\mathrm{Bu} / \mathrm{Cy}$ ablation group (3/24), $44 \%$ in the T-MSCs only group
(8/18), $50 \%$ in the T-MSCs + BMCs group (9/18) and $44 \%$ in the BMCs group (11/25). Although the survival rate of the groups injected with T-MSCs + BMCs or BMC only was improved compared with that in the $\mathrm{Bu} / \mathrm{Cy}$ only group, the difference was not statistically significant (Fig. 1B).

Changes in the body weight of the mice were also monitored from the onset of $\mathrm{Bu} / \mathrm{Cy}$ treatment, and it was observed that body weights began decreasing soon after $\mathrm{Bu} / \mathrm{Cy}$ conditioning and cell transfer. Although the mice indicated signs of weight recovery by the end of the first week following cell transplantation, their body weights subsequently decreased. Upon completion of the study, the recovered body weights of surviving mice were comparable with those of the mice in the BMC only groups: Control group (21.00 $\pm 0.83 \mathrm{~g})$, the $\mathrm{Bu} / \mathrm{Cy}$ group (17.75 $\pm 2.48 \mathrm{~g}$ ), 
Table I. Summary of BMC analysis.

\begin{tabular}{lrc}
\hline & \multicolumn{2}{c}{ Cell number } \\
\cline { 2 - 3 } Group & \multicolumn{1}{c}{ Erythroid } & Myeloid \\
\hline No treatment & $37.00 \pm 6.93$ & $56.00 \pm 6.93$ \\
Bu/Cy & $9.50 \pm 5.28$ & $8.67 \pm 3.50$ \\
T-MSCs & $20.00 \pm 5.03$ & $13.57 \pm 5.41$ \\
T-MSCs + BMCs & $16.57 \pm 5.97$ & $35.14 \pm 11.96$ \\
BMCs & $16.33 \pm 5.82$ & $11.83 \pm 3.92$ \\
\hline
\end{tabular}

Values are expressed as the mean \pm standard error of the mean $\mathrm{Bu} / \mathrm{Cy}$, busulfan/cyclophosphamide; T-MSC, tonsil-derived mesenchymal stromal cells; BMCs, bone marrow cells.

the T-MSCs group $(17.75 \pm 2.19 \mathrm{~g})$, the T-MSCs + BMCs group $(17.44 \pm 2.63 \mathrm{~g})$, and the BMC group (17.60 $\pm 2.38 \mathrm{~g}$; Fig. 1C).

T-MSC injection led to recovery of peripheral mononuclear cells. In order to compare the effect of T-MSCs on the restoration of peripheral blood cells, blood smear slides were stained and differential cell counts were analyzed among the groups. Cell populations from the control group exhibited normal morphology and the $\mathrm{Bu} / \mathrm{Cy}$ group demonstrated scant density of RBCs, leukocytes, and platelets, although the morphology for each of the cells was near normal (Fig. 2A). However, RBC counts indicated that the BMCs group $\left(25.25 \pm 3.18 \times 10^{6}\right)$ almost recovered to the level of the control $\left(36.50 \pm 2.12 \times 10^{6}\right)$. The $\mathrm{Bu} / \mathrm{Cy}$ group $\left(10.00 \pm 2.83 \times 10^{6}\right)$, T-MSCs group $\left(13.85 \pm 6.86 \times 10^{6}\right)$, and T-MSCs + BMCs group $\left(20.27 \pm 1.41 \times 10^{6}\right)$ did not fully recover to normal and were significantly different; Fig. 2B). Leukocyte counts were lowest in the $\mathrm{Bu} / \mathrm{Cy}$ group $\left(3.40 \pm 0.28 \times 10^{5}\right)$ and also in the T-MSCs group $\left(6.00 \pm 0.56 \times 10^{5}\right)$. Notably, in the T-MSCs + BMCs groups, leukocyte counts $\left(34.13 \pm 5.00 \times 10^{5}\right)$ recovered to above normal (control group) levels $\left(25.20 \pm 5.01 \times 10^{5}\right)$ while those of the BMCs group were lower than normal $\left(8.70 \pm 1.27 \times 10^{5}\right.$; Fig. $\left.2 \mathrm{C}\right)$. Therefore, these results indicate a potential favorable effect on myelopoiesis resulting from co-transplantation of T-MSCs with allogeneic BMCs.

T-MSCs have a beneficial effect on BM reconstitution. To evaluate the effect of T-MSCs on BM reconstitution, the cellular densities of decalcified bone sections from each group were determined by $\mathrm{H} \& \mathrm{E}$ staining. The BM of mice from the control group was filled with various erythroid and myeloid cells, small adipocytes and a small number of megakaryocytes (Fig. 3A). The marrow space in the $\mathrm{Bu} / \mathrm{Cy}$ treatment group was almost completely replaced by adipocytes and was vacant of cells of hematopoietic lineage. The T-MSCs group demonstrated increased BMC density compared with the $\mathrm{Bu} / \mathrm{Cy}$ group (Fig. 3B). The marrow space of the co-transplantation group, T-MSCs + BMCs, was also filled with various BMCs, and a number of adipocytes and megakaryocytes. The BM cellular density was assessed by calculating the mean ratio of the area of BMCs to adipose cells in $>10$ different fields per slide. This quantitative analysis demonstrated higher BMC density in groups that received T-MSCs + BMCs compared with any other
A

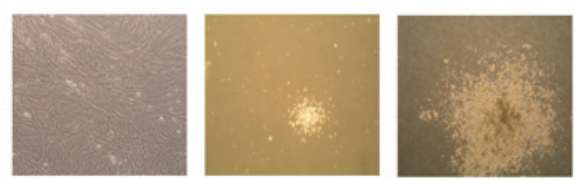

B

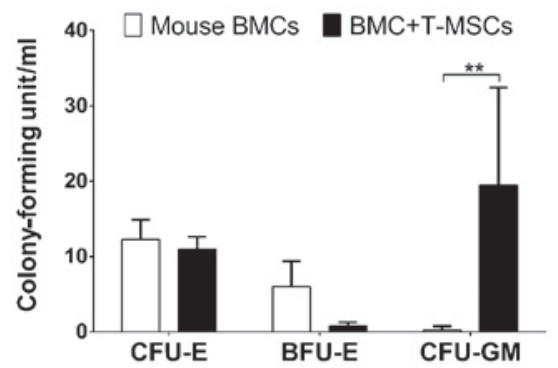

Figure 4. Methylcellulose colony forming assay. (A) Representative images of colony formation in MethoCult ${ }^{\circledR}$ media following three weeks of culture: T-MSCs (left), small CFU-E on mouse BMC plate (middle), large CFU-GM on BMC with T-MSCs (right); magnification, x100. (B) Colonies from triplicated culture plates were counted (according to colony size and cellular composition) and presented in $1 \mathrm{ml}$ media; ${ }^{* *} \mathrm{P}<0.01$. Values are expressed as the mean \pm standard error of the mean. CFU-E, colony-forming unit-erythroid; BFU-E, burst-forming unit-erythroid; CFU-GM, colony-forming unit-granulocyte/macrophage; BMC, bone marrow cell; T-MSC, tonsil-derived mesenchymal stromal cell.

treatment group $(62.81 \pm 10.32 \%$ vs. control, $75.71 \pm 3.63 \%)$ and those of the $\mathrm{Bu} / \mathrm{Cy}$ group were the lowest $(16.87 \pm 5.48 \%)$. As indicated in Fig. 3B, the BM cellularity of the T-MSCs + BMCs groups was almost normal (control; 75.71 $\pm 3.63 \%$ ). In the T-MSCs $(37.97 \pm 8.19 \%)$ or BMCs only groups $(33.29 \pm 6.98 \%)$, cellularity was significantly different from the normal control.

BM smears were stained and analyzed to determine the composition of cells with erythroid or myeloid lineage in the BM (Fig. 3C). For erythroid cells, all Bu/Cy-treated groups demonstrated decreased cell numbers and insufficient recovery (Fig. 3D). However, for myeloid cells in the BM smear, the cell numbers observed in the T-MSCs + BMCs groups were higher than those of other $\mathrm{Bu} / \mathrm{Cy}$-treated groups (the $\mathrm{Bu} / \mathrm{Cy}$, T-MSCs and BMCs groups; Table I).

T-MSCs enhanced colony formation in methylcellulose assay. To determine the effect of T-MSCs on proliferation and differentiation of BMCs in vitro, a methylcellulose colony assay $\left(\right.$ MethoCult ${ }^{\circledR}$ ) was performed to evaluate erythroid and myeloid lineage differentiation from BM cells (Fig. 4A). Fibroblast-like cells were grown in MethoCult ${ }^{\circledR}$ dishes with T-MSC-only conditions and it was observed that the T-MSCs did not differentiate into hematopoietic lineage cells. For erythroid lineage cells, there was no significant difference between cells in the BMCs [colony-forming unit-erythroid (CFU-E), $12.25 \pm 2.63 \mathrm{U} / \mathrm{ml}$; burst-forming unit-erythroid (BFU-E), $6.00 \pm 3.37 \mathrm{U} / \mathrm{ml}]$ and the T-MSCs + BMCs groups (CFU-E, $11.00 \pm 1.63 \mathrm{U} / \mathrm{ml}$; BFU-E, $0.75 \pm 0.50 \mathrm{U} / \mathrm{ml})$. For the myeloid lineage, however, CFU-granulocyte/macrophage was significantly higher in T-MSCs + BMCs isolated from mice $(19.50 \pm 12.92 \mathrm{U} / \mathrm{ml})$ compared with those of BMCs only $(0.25 \pm 0.50 \mathrm{U} / \mathrm{ml}$; Fig. 4B). Thus, T-MSCs exerted a greater effect on myeloid differentiation of mice BMCs than on erythroid lineage cells. 


\section{Discussion}

In the present study, the effect of human T-MSCs on BM reconstitution was investigated in a mouse allogeneic BMT model. Co-transplantation of T-MSCs with BMCs was demonstrated to be associated with increased myelopoiesis in vivo and in vitro.

BMT frequently induces GVHD, which results in engraftment failure; thus, long-term immune suppression treatment is required to prevent GVHD. Currently, co-transplantation of MSCs along with HSCs in HSCT or BMT is being actively investigated to minimize the continuous use of immunosuppressive therapeutic agents, reduce the incidence of GVHD syndrome and promote allograft survival $(20,21)$.

To analyze the possible mechanism underlying the positive effect of T-MSCs on BM reconstruction, $\mathrm{PKH} 26$-stained T-MSCs in the BM were localized following infusion in $\mathrm{Bu} / \mathrm{Cy}$-treated mice. However, PKH-positive cells were not observed in the BM in these mice (data not shown). Although MSCs have multi-lineage potential to differentiate into various mature cells in vitro, they are rarely observed to truly engraft and survive in damaged host tissue (22). The present study also aimed to investigate whether T-MSCs differentiate into hematopoietic cells. The hematopoiesis potential was analyzed using MethoCult ${ }^{\circledR}$ medium culture, which indicated that no differentiation of T-MSCs into hematopoietic lineage cells had taken place, however, myeloid lineage cells (such as CFU-GM) increased. To evaluate how T-MSCs positively affected BM reconstruction, the cellular constitution in mouse BM and in peripheral blood was analyzed. Results of the current study demonstrated an increase of myeloid lineage cells in the T-MSCs + BMCs group, which was consistent with the increase of the CFU-GM colony in the in vitro experiment.

The present study also investigated the quantity of adipose tissue occupying the medullary space in the BM following conditioning chemotherapy. Histological findings indicated a relative increase in adipose tissue in the BM space of mice in the $\mathrm{Bu} / \mathrm{Cy}$ chemotherapy group. A recent review indicated that increased adipocytes in the BM space damage the microenvironmental balance necessary to maintain hematopoiesis or osteogenesis, and disturb the interaction between HSCs and other cells (23). The findings of the present study suggested that increased adipocytes in the BM interrupt BMC engraftment, which is prevented or attenuated by T-MSCs. Future studies are required to define a mechanism for the enhancement of BM reconstitution by T-MSCs and to determine the mechanism by which the secretory function of T-MSCs is altered in the BM microenvironment.

Previous studies demonstrated that infused MSCs exert their effects via secreted trophic signals without localization within the damaged tissue (24). These regulatory and trophic factors, which are secreted by MSCs, include cytokines, chemokines and growth factors that are broadly defined as the MSC secretome (25). These trophic factors provide a supportive microenvironment for the regeneration of injured tissue, and decrease inflammation via modulation of cell survival, cell renewal, cell differentiation, inflammation and angiogenesis $(2,5,22,26)$. The secretome of T-MSCs may be critical in BM reconstitution and future studies are required to investigate the secretory function of T-MSCs in vivo.
In conclusion, results from the current study suggest that the co-transplantation of T-MSCs with HSCs promotes successful $\mathrm{BM}$ engraftment in delayed or defective BM engraftment patients by enhancing myelopoiesis and possibly megakaryocytosis.

\section{Acknowledgements}

The present study was supported by the Basic Science Research Program through the National Research Foundation of Korea, which was funded by the Ministry of Education, Science, and Technology (grant no. 2012M3A9C6049823).

\section{References}

1. Dexter TM, Spooncer E, Schofield R, Lord BI and Simmons P: Haemopoietic stem cells and the problem of self-renewal. Blood Cells 10: 315-339, 1984.

2. Pittenger MF, Mackay AM, Beck SC, Jaiswal RK, Douglas R, Mosca JD, Moorman MA, Simonetti DW, Craig S and Marshak DR: Multilineage potential of adult human mesenchymal stem cells. Science 284: 143-147, 1999.

3. Toma C, Pittenger MF, Cahill KS, Byrne BJ and Kessler PD: Human mesenchymal stem cells differentiate to a cardiomyocyte phenotype in the adult murine heart. Circulation 105: 93-98, 2002.

4. Sanchez-Ramos J, Song S, Cardozo-Pelaez F, Hazzi C, Stedeford T, Willing A, Freeman TB, Saporta S, Janssen W, Patel N, et al: Adult bone marrow stromal cells differentiate into neural cells in vitro. Exp Neurol 164: 247-256, 2000.

5. Kim EJ, Kim N and Cho SG: The potential use of mesenchymal stem cells in hematopoietic stem cell transplantation. Exp Mol Med 45: e2, 2013.

6. Kern S, Eichler H, Stoeve J, Klüter H and Bieback K: Comparative analysis of mesenchymal stem cells from bone marrow, umbilical cord blood, or adipose tissue. Stem Cells 24: 1294-1301, 2006.

7. Le Blanc K, Samuelsson H, Gustafsson B, Remberger M, Sundberg B, Arvidson J, Ljungman P, Lönnies H, Nava S and Ringdén O: Transplantation of mesenchymal stem cells to enhance engraftment of hematopoietic stem cells. Leukemia 21: 1733-1738, 2007

8. Macmillan ML, Blazar BR, DeFor TE and Wagner JE: Transplantation of ex-vivo culture-expanded parental haploidentical mesenchymal stem cells to promote engraftment in pediatric recipients of unrelated donor umbilical cord blood: Results of a phase I-II clinical trial. Bone Marrow Transplant 43: 447-454, 2009.

9. Joo SY, Cho KA, Jung YJ, Kim HS, Park SY, Choi YB, Hong KM, Woo SY, Seoh JY, Cho SJ and Ryu KH: Mesenchymal stromal cells inhibit graft-versus-host disease of mice in a dose-dependent manner. Cytotherapy 12: 361-370, 2010.

10. Le Blanc K, Frassoni F, Ball L, Locatelli F, Roelofs H, Lewis I, Lanino E, Sundberg B, Bernardo ME, Remberger M, et al; Developmental Committee of the European Group for Blood and Marrow Transplatation: Mesenchymal stem cells for treatment of steroid-resistant, severe, acute graft-versus-host disease: A phase II study. Lancet 371: 1579-1586, 2008.

11. Le Blanc K, Rasmusson I, Sundberg B, Götherström C, Hassan M, Uzunel M and Ringdén O: Treatment of severe acute graft-versus-host disease with third party haploidentical mesenchymal stem cells. Lancet 363: 1439-1441, 2004.

12. Dalle Carbonare L, Valenti MT, Zanatta M, Donatelli L and Lo Cascio V: Circulating mesenchymal stem cells with abnormal osteogenic differentiation in patients with osteoporosis. Arthritis Rheum 60: 3356-3365, 2009.

13. Huang GT, Gronthos S and Shi S: Mesenchymal stem cells derived from dental tissues vs. those from other sources: Their biology and role in regenerative medicine. J Dent Res 88: 792-806, 2009.

14. Blazar BR, Murphy WJ and Abedi M: Advances in graft-versus-host disease biology and therapy. Nat Rev Immunol 12: 443-458, 2012.

15. Almeida-Porada G, Flake AW, Glimp HA and Zanjani ED: Cotransplantation of stroma results in enhancement of engraftment and early expression of donor hematopoietic stem cells in utero. Exp Hematol 27: 1569-1575, 1999. 
16. Nolta JA, Hanley MB and Kohn DB: Sustained human hematopoiesis in immunodeficient mice by cotransplantation of marrow stroma expressing human interleukin-3: Analysis of gene transduction of long-lived progenitors. Blood 83: 3041-3051, 1994.

17. Angelopoulou M, Novelli E, Grove JE, Rinder HM, Civin C, Cheng L and Krause DS: Cotransplantation of human mesenchymal stem cells enhances human myelopoiesis and megakaryocytopoiesis in NOD/SCID mice. Exp Hematol 31: 413-420, 2003.

18. Ryu KH, Cho KA, Park HS, Kim JY, Woo SY, Jo I, Choi YH, Park YM, Jung SC and Chung SM: Tonsil-derived mesenchymal stromal cells: Evaluation of biologic, immunologic and genetic factors for successful banking. Cytotherapy 14: 1193-1202, 2012.

19. Kim SJ, Park MH, Moon HJ, Park JH, Ko Y and Jeong B Polypeptide thermogels as a three dimensional culture scaffold for hepatogenic differentiation of human tonsil-derived mesenchymal stem cells. ACS Appl Mater Interfaces 6: 17034-17043, 2014

20. Lechler RI, Sykes M, Thomson AW and Turka LA: Organ transplantation - how much of the promise has been realized? Nat Med 11: 605-613, 2005.
21. Bluestone JA, Thomson AW, Shevach EM and Weiner HL: What does the future hold for cell-based tolerogenic therapy? Nat Rev Immunol 7: 650-654, 2007.

22. Kupcova Skalnikova H: Proteomic techniques for characterisation of mesenchymal stem cell secretome. Biochimie 95 2196-2211, 2013.

23. Adler BJ, Kaushansky K and Rubin CT: Obesity-driven disruption of haematopoiesis and the bone marrow niche. Nat Rev Endocrinol 10: 737-748, 2014.

24. Lai RC, Tan SS, Teh BJ, Sze SK, Arslan F, de Kleijn DP, Choo A and Lim SK: Proteolytic potential of the MSC exosome proteome: Implications for an exosome-mediated delivery of therapeutic proteasome. Int J Proteomics 2012: 971907, 2012.

25. Ranganath SH, Levy O, Inamdar MS and Karp JM: Harnessing the mesenchymal stem cell secretome for the treatment of cardiovascular disease. Cell Stem Cell 10: 244-258, 2012.

26. Le Blanc K and Pittenger M: Mesenchymal stem cells: Progress toward promise. Cytotherapy 7: 36-45, 2005. 